\title{
Cervical Spinal Cord Injury During Coronary Artery Bypass Graft Surgery in An Elderly: A Case Report
}

Keiji Nagata*, Akihito Minamide, Masanari Takami, Takeshi Deguchi, Takashi Shimoe and Hiroshi Yamada

*The department of orthopedic surgery, Japan

*Corresponding author: Keiji Nagata, The department of orthopedic surgery, Japan.

\section{Case Report}

Intraoperative spinal cord injury (SCI) is uncommon and the pathology has not cleared. We report cervical cord injury without vertebral fracture during a coronary artery bypass operation. Cervical cord compression (CCC) is compression of the cervical spinal cord that occurs during the normal course of aging and may progress into cervical spondylotic myelopathy (CSM), which can cause neurologic dysfunction. Many people with cervical cord compression are asymptomatic. However, patients with CCC are at higher risk of SCI following minor injury. An 85-year-old woman with asymptomatic cervical cord compression underwent a coronary artery bypass graft surgery. After the surgery, he developed tetraplegia. MRI revealed severe spinal cord compression from C3 to C7 and C5/6 signal change of spinal cord (Figure 1). The radiograph and CT showed diffuse idiopathic skeletal hyperostosis and thoracic kyphosis of 55 degree (Figure 2). Cervical SCI after was diagnosed. After the diagnosis, we underwent laminoplasty (Figure 3). And he almost completely recovered after surgery.

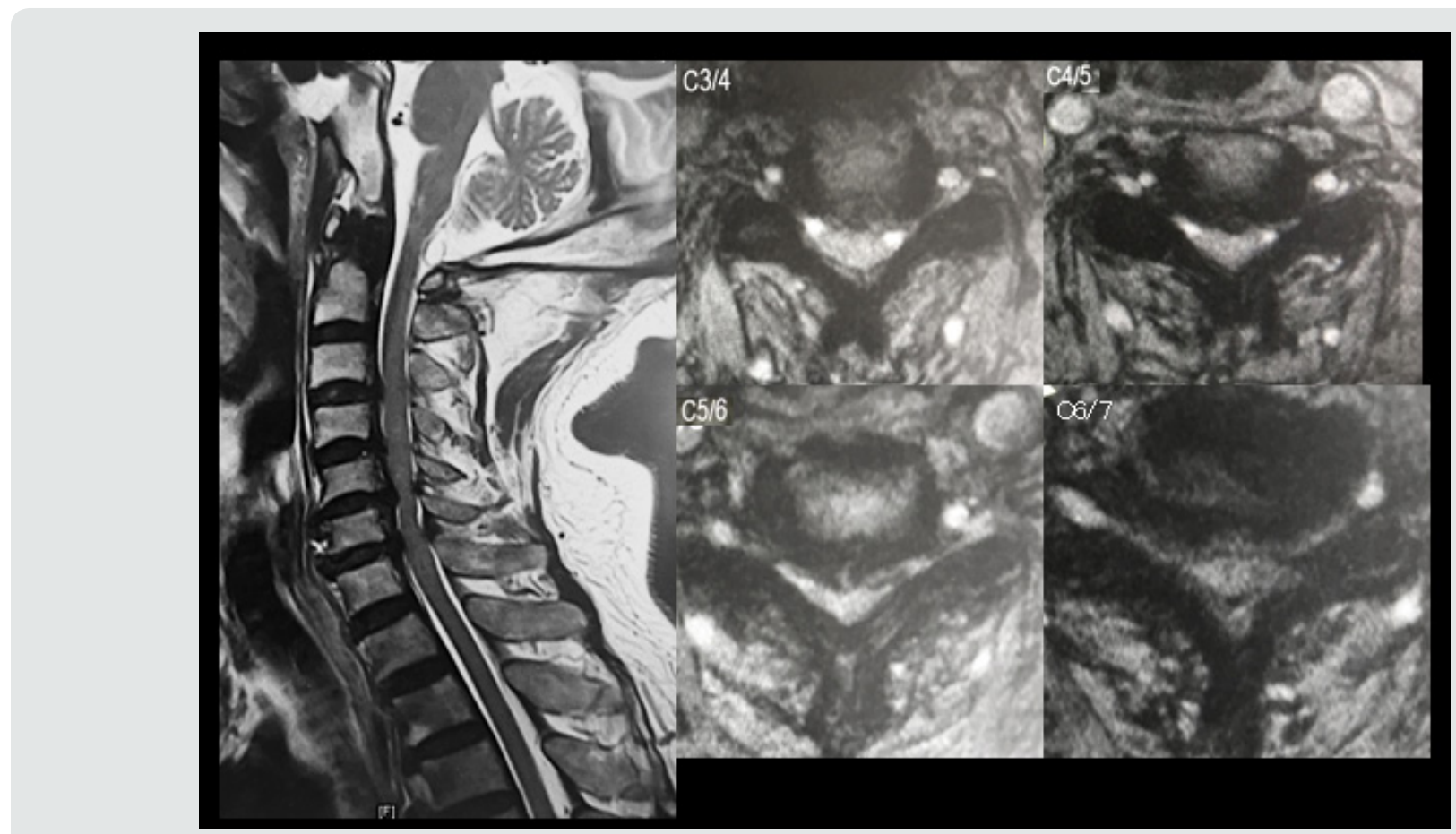

Figure 1: Magnetic resonance imaging (MRI) of the cervical spine. 


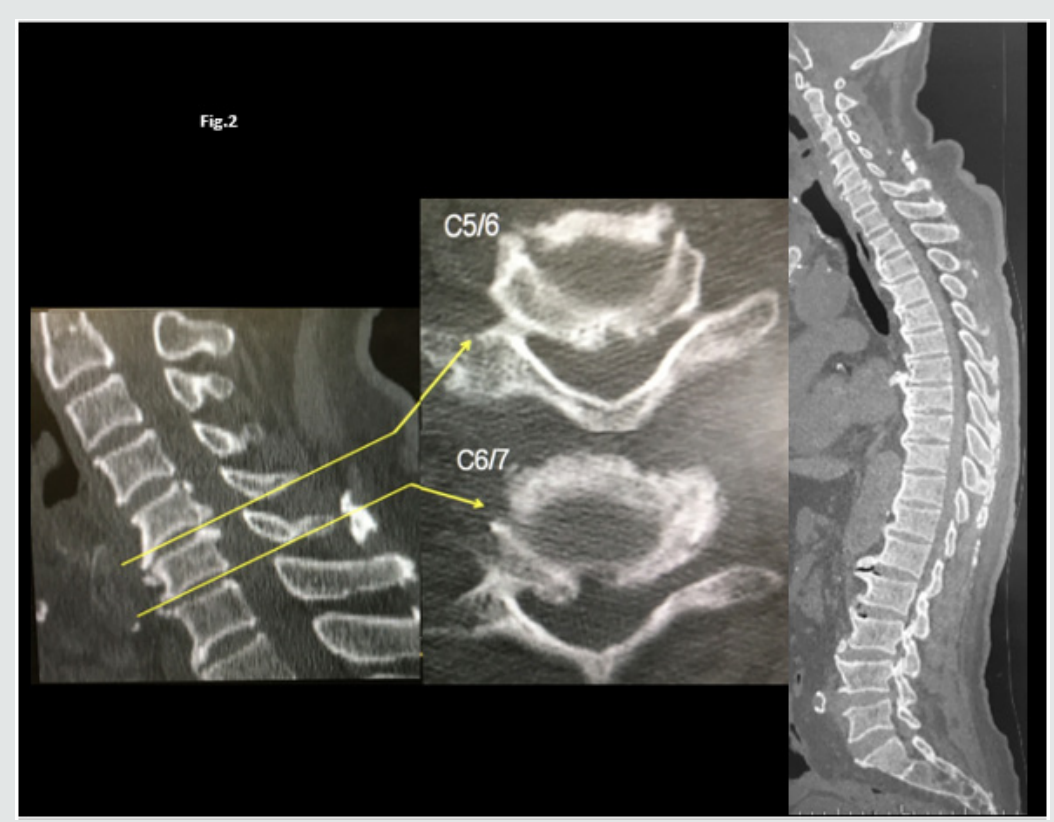

Figure 2: MRI showed multilevel spinal cord compression.

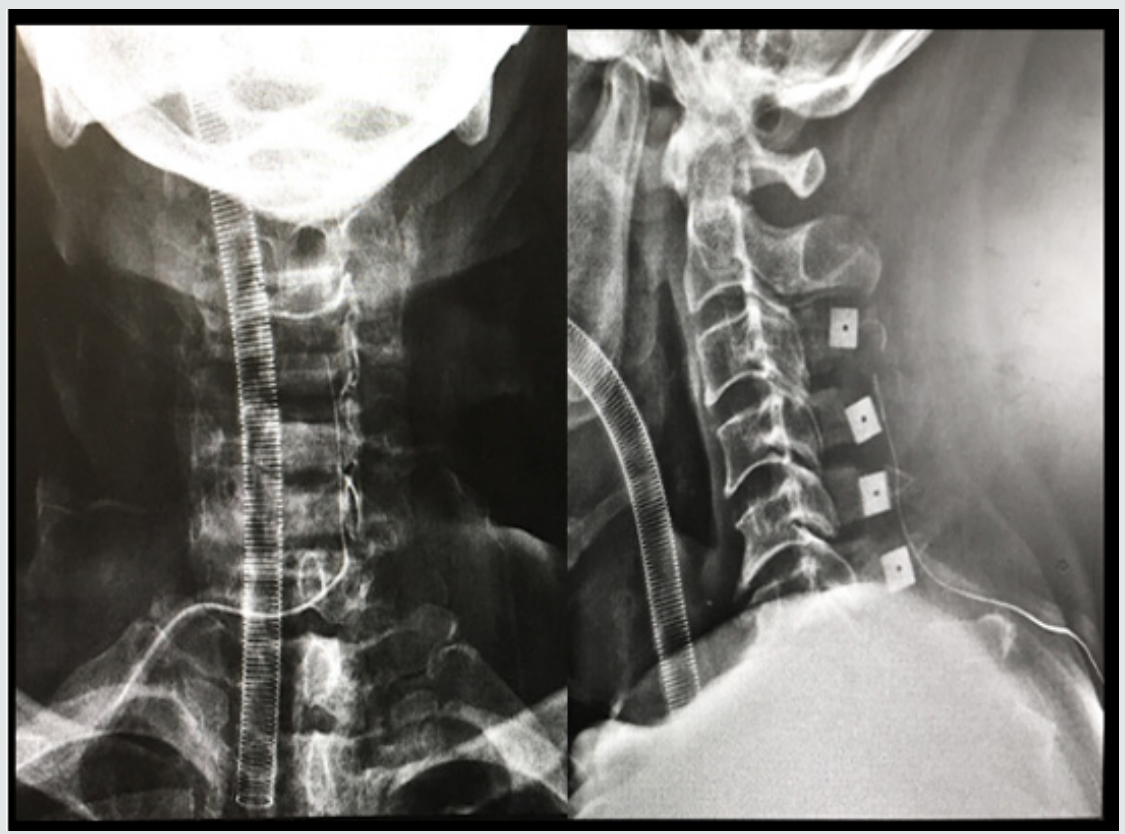

Figure 3: The radiograph and CT showed diffuse idiopathic skeletal hyperostosis and thoracic kyphosis Radiograph after laminoplasty for cervical spinal cord injury.

Iatrogenic cervical SCI after non spinal surgeries that requires neck hyperextension is rarely reported, probably due to underdiagnosis and underreport. In the current aging society, the prevalence of patients with CCC is expected to increase. In our population-based magnetic resonance imaging (MRI) study, the prevalence rate of CCC was $24.4 \%$, and it was higher with increasing age in both men and women [1]. Among the 15 cases (including ours) published in the literature [2], most patients had cervical cord compression and were old men. Eight patients had undergone coronary artery bypass surgery that requires prolonged operative time. Only 3 patients had almost complete recovery.
Two patients required tracheostomy for long-term ventilator support. Two patients died. These cases reiterate the potential risk of iatrogenic SCI in people with predisposing conditions such as cervical spondylosis and CCC. Moreover, in this case, the patient had diffuse idiopathic skeletal hyperostosis and thoracic kyphosis of 55 degree, which can lead inflexibility of spine. The inflexibility of thoracic spine might cause hyperextension of cervical spine during the surgery. Surgeries requiring prolonged neck hyperextension put patients with cervical spondylosis and CCC at risk for SCI. It is essential to recognize the potential occurrence of iatrogenic SCI might endanger patients' lives. 


\section{References}

1. Nagata K, Yoshimura N, Yoshida M (2012) Prevalence of cervical cord compression and its association with physical performance in a population-based cohort in Japan: The Wakayama Spine Study. Spine 37(22): 1892-1898.

\section{(c) (i) \\ This work is licensed under Creative Commons Attribution 4.0 License}

To Submit Your Article Click Here:

Submit Article
2. W Xiong, F Li, H Guan (2015) Tetraplegia After Thyroidectomy in a Patient with Cervical Spondylosis A Case Report and Literature Review 94(6): e524.

DOI: $10.32474 /$ SCSOAJ.2019.02.000143

$\begin{gathered}\text { Surgery \& Case Studies: Open } \\ \text { Access Journal }\end{gathered}$
Assets of Publishing with us
- Global archiving of articles
- Immediate, unrestricted online access
- Rigorous Peer Review Process
- Authors Retain Copyrights
- Unique DOI for all articles

